\title{
Características produtivas, qualitativas e microbiológicas de galinhas poedeiras alimentadas com diferentes níveis de complexo enzimático
}

\section{Performance, qualitative and microbiogy characteristics of laying hens fed with different levels of enzyme complex}

\author{
Alexandre $\mathrm{Oba}^{1 *}$; João Waine Pinheiro ${ }^{1}$; Caio Abércio da Silva ${ }^{1}$; \\ Raúl Jorge Hernan Castro-Gomez²; Carla Renata Benitez³; Fábio Yukio Ueno ${ }^{4}$; \\ Cesar Aparecido Borges ${ }^{5}$; Maurício de Almeida ${ }^{6}$
}

\begin{abstract}
Resumo
Este trabalho teve por objetivo avaliar o desempenho de galinhas poedeiras alimentadas com diferentes níveis de complexo enzimático a base de fitase, celulase, pectinase, protease, amilase, betaglucanase e xilanase. Foram utilizadas 328 poedeiras leves da linhagem Shaver White, com 60 semanas de idade. As aves foram distribuídas em cinco tratamentos, que consistiam em diferentes níveis de complexo enzimático $(0,50,100,150$ e $200 \mathrm{ppm})$. Foram avaliados o desempenho das aves, qualidade da casca dos ovos, qualidade interna dos ovos, $\mathrm{pH}$ e viscosidade do conteúdo intestinal, matéria seca e mineral das fezes e microbiologia do conteúdo do intestino delgado. Os resultados mostraram que a adição do complexo enzimático nas rações à base de milho e farelo de soja de galinhas de postura velhas não proporcionou melhorias no desempenho das aves, qualidade da casca e interna dos ovos, matéria seca e mineral das fezes e microbiologia do conteúdo intestinal, porém houve resposta linear significativa quando se aumentou os níveis do complexo enzimático, onde este proporcionou um aumento do $\mathrm{pH} \mathrm{e}$ uma menor viscosidade da digesta do intestino delgado.
\end{abstract}

Palavras-chave: Aditivos, ave, enzimas, microbiologia, nutrição, qualidade ovo

\begin{abstract}
This study aimed to evaluate the performance of laying hens fed different levels of the enzyme complex (phytase, cellulase, pectinase, protease, amylase, beta-glucanase e xylanase). 328 laying hens were used Shaver White strain at 60 weeks of age. The birds were distributed into five treatments, involving different levels of enzyme complex $(0,50,100,150$ and $200 \mathrm{ppm})$. We evaluated the performance of laying hens, egg shell quality, internal egg quality, $\mathrm{pH}$ and viscosity of the intestinal contents, dry matter and mineral in the excreta and microbiology of the contents in the small intestine. The results showed that the addition of the enzyme complex in diets based on corn and soybean meal for laying hens old did not improve on broiler performance, eggshell and internal egg quality, dry matter and mineral content in the excreta and microbiology of the contents in the small intestine. However there was a significant linear response when increased levels of the enzyme complex, where it caused an increase in $\mathrm{pH}$ and a
\end{abstract}

\footnotetext{
${ }^{1}$ Profs. Drs. do Dept ${ }^{\mathrm{o}}$ de Zootecnia da Universidade Estadual de Londrina, UEL, Londrina, PR. E-mail: oba@uel.br; jwaine@uel. br; casilva@uel.br

${ }^{2}$ Prof. do Dept ${ }^{\circ}$ de Ciência e Tecnologia de Alimentos, UEL, Londrina, PR. E-mail: rcastrog@yahoo.com

${ }^{3}$ Zootecnista da Empresa Big Frango, Rolândia, PR. E-mail: latoboratorio@nutribig.com.br

${ }^{4}$ Zootecnista, UEL, Londrina, PR. E-mail:phabiozoo@hotmail.com

${ }^{5}$ M.e em Ciência Animal da Phibro Animal Health, Campo Grande, MS. E-mail: borges.cesar@gmail.com

${ }^{6}$ Discente de Doutorado do Programa de Pós-graduação em Ciência Animal, UEL, Londrina, PR. E-mail: mauricio_alm_jn@hotmail.com

* Autor para correspondência
} 
lower viscosity of digesta within the small intestine.

Key words: Additive, egg quality, enzymes, microbiology, nutrition, poultry

\section{Introdução}

$\mathrm{O}$ alto custo dos ingredientes utilizados nas rações das aves tem levado ao desenvolvimento de inúmeros aditivos com o intuito de melhorar o aproveitamento dos nutrientes. Entre estes aditivos tem-se dado grande destaque as enzimas exógenas, visto que estas atuam em frações não disponíveis aos animais monogástricos. Entre estas frações, segundo Costa et al. (2004) estão o fósforo fítico e os polissacarídios não-amídicos (PNAs). Este último, além de não sofrer digestão, ainda prejudica a digestão e absorção de outros nutrientes, visto que se hidrata e aumenta a viscosidade da digesta, prejudicando assim a ação das enzimas endógenas e a absorção das moléculas simples, como glicose e aminoácidos livres. Já o ácido fítico, além de reduzir a disponibilidade do fósforo, prejudica ainda a absorção de $\mathrm{Zn}, \mathrm{Ca}, \mathrm{Fe}$ e $\mathrm{Mg}$. Além disto, segundo Bedford (2000) as enzimas promovem a redução da variação da qualidade nutricional das dietas, digestão mais rápida e completa, redução da excreção fecal de nutrientes e consequentemente da poluição ambiental, além de reduzir a incidência de fezes úmidas quando as aves são alimentadas com dietas de alta viscosidade.

Em função do exposto, este trabalho tem por objetivo avaliar a adição on top de diferentes níveis do complexo enzimático na alimentação de galinhas poedeiras velhas e analisar as características de desempenho zootécnico, qualidade dos ovos, da digesta e da microbiologia intestinal.

\section{Material e Métodos}

O experimento foi conduzido no setor de avicultura da Universidade Estadual de Londrina e foram utilizadas 360 galinhas poedeiras da linhagem Shaver White, com 60 semanas de idade e no primeiro ciclo de postura. O manejo utilizado foi o tradicionalmente empregado nas granjas comerciais, com água e alimento à vontade, iluminação de 17 horas, durante o período experimental de 84 dias, divididos em três ciclos de 28 dias, sendo que o fornecimento de ração foi realizado duas vezes ao dia e a coleta dos ovos foi realizada no final da tarde. As rações experimentais foram formuladas para atender as exigências mínimas propostas por Rostagno et al. (2005) conforme Tabela 1. O complexo enzimático era composto pelas enzimas fitase, celulase, pectinase, protease, amilase, betaglucanase e xilanase. A adição deste complexo enzimático foi realizado na forma on top, ou seja, sem ocorrer reformulação das dietas, sendo utilizadas as seguintes adições deste complexo: 50, 100,150 e 200 ppm.

As aves foram alojadas em gaiolas de arame galvanizado, medindo $100 \mathrm{~cm}$ de comprimento, dividida em 4 compartimentos de $25 \mathrm{~cm}$ de largura, $45 \mathrm{~cm}$ de profundidade e $40 \mathrm{~cm}$ de altura, sendo que em cada compartimento foram alojadas duas aves, totalizando oito aves por gaiola, que correspondia a uma unidade experimental. $\mathrm{O}$ delineamento experimental adotado foi inteiramente casualizado, com diferentes números de repetições, isto é, foram utilizadas 5 repetições para o tratamento controle e 10 repetições para os tratamentos com adição do complexo enzimático, sendo que cada repetição era composta por 8 aves.

Ao final de cada ciclo, nos dois últimos dias, os ovos foram pesados para determinar o peso médio destes, que foram utilizados para estimar o peso total de ovos produzidos no período experimental. As variáveis estudadas foram: porcentagem de postura, peso médio dos ovos, consumo de ração por ave, conversão alimentar e porcentagem de ovos trincados. Para as análises de qualidade dos ovos, no final de cada ciclo foram pegos dois ovos de cada parcela experimental, os quais foram submetidos às 
análises de porcentagem de casca, albúmen e gema, através da pesagem do ovo, da gema e da casca, sendo que o peso do albúmen foi determinado através da diferença entre o peso do ovo e peso da casca mais o peso da gema. A Unidade Haugh foi determinada através do método descrito por Souza et al. (1994), a espessura de casca foi avaliada através da medição da casca em quatro pontos, por um paquímetro, após as cascas serem lavadas e secas, e matéria mineral foi determinada através de sua queima em mufla (AOAC, 1990).

Tabela 1. Composição da dieta experimental.

\begin{tabular}{|c|c|}
\hline \multicolumn{2}{|l|}{ Ingredientes } \\
\hline Milho & 65,92 \\
\hline Farelo de soja $45 \%$ & 22,40 \\
\hline Calcário & 8,99 \\
\hline Fosfato bicálcico & 1,43 \\
\hline Óleo de soja & 0,26 \\
\hline Sal & 0,47 \\
\hline Suplemento vitamínico-mineral ${ }^{1}$ & 0,25 \\
\hline DL-metionina & 0,27 \\
\hline L-Lisina & 0,01 \\
\hline Total & 100,00 \\
\hline \multicolumn{2}{|l|}{ Composição calculada } \\
\hline Proteína bruta $(\%)$ & 16,02 \\
\hline Energia Metabolizável (kcal/kg) & 2800 \\
\hline Cálcio $(\%)$ & 3,90 \\
\hline Fósforo disponível (\%) & 0,36 \\
\hline Lisina digestível (\%) & 0,71 \\
\hline Metionina digestível (\%) & 0,50 \\
\hline Metionina + cistina digestível $(\%)$ & 0,72 \\
\hline Sódio $(\%)$ & 0,22 \\
\hline \multicolumn{2}{|c|}{$\begin{array}{l}{ }^{1} \text { Composição do produto }(\mathrm{kg})-\text { vit } \mathrm{A}-3.600 .000 \mathrm{UI} \text {, vit D3 } \\
-1.000 .000 \text { UI, vit } \mathrm{E}-3.200 \mathrm{mg} \text {, vit } \mathrm{B} 1-223 \mathrm{mg} \text {, vit } \mathrm{B} 2 \\
-1.600 \mathrm{mg} \text {, vit } \mathrm{B} 6-421 \mathrm{mg} \text {, vit } \mathrm{B} 12-4.000 \mu \mathrm{g} \text {, vit } \mathrm{K} 3- \\
806 \mathrm{mg} \text {, pantotenato de cálcio }-3.210 \mathrm{mg} \text {, niacina }-8.000 \mathrm{mg} \text {, } \\
\text { metionina }-360.000 \mathrm{mg} \text {, colina }-112.000 \mathrm{mg} \text {, antioxidante - } \\
4.000 \mathrm{mg} \text {, zinco }-25.200 \mathrm{mg} \text {, ferro }-19.600 \mathrm{mg} \text {, manganês - } \\
31.000 \mathrm{mg} \text {, cobre }-6.125 \mathrm{mg} \text {, cobalto }-80 \mathrm{mg} \text {, iodo }-387 \mathrm{mg} \text {, } \\
\text { selênio }-101 \mathrm{mg} \text {. } \\
\text { Fonte: Elaboração dos autores. }\end{array}$} \\
\hline
\end{tabular}

No final do período experimental as excretas das aves foram coletadas em toalhas plásticas, por um período de três horas a partir do momento do nascer do sol, visando coletar maior quantidade de fezes e minimizar a perda de umidade para o ambiente. Em seguida, estas foram acondicionadas individualmente em sacos plásticos e encaminhadas para o laboratório, onde foram homogeneizadas para a quantificação da matéria seca e determinação da porcentagem de cinzas. Também no final do experimento foram sacrificadas por deslocamento cervical duas aves por parcela experimental, onde se coletou todo o intestino delgado, para análises de viscosidade da digesta, $\mathrm{pH}$ e microbiologia intestinal. Após a extração do conteúdo intestinal, este foi submetido à análise de $\mathrm{pH}$ através de peagâmetro digital da marca Gehaka, modelo PG 2000. A viscosidade foi determinada após a digesta ser centrifugada e o sobrenadante submetido a análise em viscosímetro Broksfield, conforme Almirall et al. (1995). Nas mesmas amostras foi retirada uma alíquota para determinação de lactobacilos, salmonela (kit Revel Microbial Screening Test), coliformes totais e fecais, conforme técnicas descritas por Siqueira (1995).

Os valores de cada unidade experimental foram comparadas pelo Teste de Tukey a 5\% de significância e submetidas à análise de regressão, através do programa SAEG (Sistema para Análises Estatísticas e Genéticas), desenvolvido pela UFV (2000).

\section{Resultados e Discussão}

Os resultados obtidos na Tabela 2 mostram que a adição do complexo enzimático na alimentação de galinhas de postura no final de ciclo de produção não influenciou nos parâmetros produtivos. Estes resultados estão de acordo com os encontrados por Freitas, Fuentes e Espíndola (2000) que ao fornecer complexo enzimático à base de $\alpha$-amilase, xilanase e protease a galinhas velhas de 68 semanas, em segundo ciclo de postura, recebendo rações isoproteicas, porém com diferentes níveis de energia ( 2850 ou $2750 \mathrm{kcal} \mathrm{EM} / \mathrm{kg}$ ) e com ou sem $0,1 \%$ do complexo enzimático, em uma dieta 
a base de milho, farelo de soja e farelo de trigo, não observaram qualquer efeito dos diferentes tratamentos, sobre os dados produtivos. Este trabalho mostrou que o complexo enzimático independentemente do nível utilizado não alterou o aproveitamento dos nutrientes ou os animais não precisaram de maiores quantidades de nutrientes que o fornecido pelo tratamento controle.

Tabela 2. Resultados de porcentagem de postura, peso médio dos ovos (PMO), consumo de ração (CR), conversão alimentar (CA) e porcentagem de ovos trincados de galinhas poedeiras alimentadas com diferentes níveis de inclusão on top de complexo enzimático.

\begin{tabular}{cccccc}
\hline Níveis Complexo enzimático & \% Postura & PMO $(\mathrm{g})$ & $\mathrm{CR}(\mathrm{g} /$ ave/dia) & $\mathrm{CA}$ & \% ovos trincados \\
\hline Controle & 77,90 & 64,76 & 104,28 & 2,08 & 3,43 \\
$50 \mathrm{ppm}$ & 76,89 & 64,91 & 105,15 & 2,13 & 4,82 \\
$100 \mathrm{ppm}$ & 77,52 & 63,34 & 104,05 & 2,20 & 4,60 \\
$150 \mathrm{ppm}$ & 76,31 & 64,85 & 105,24 & 2,14 & 4,24 \\
$200 \mathrm{ppm}$ & 79,54 & 64,50 & 104,80 & 2,06 & 4,38 \\
\hline Efeito & NS & NS & NS & NS & NS \\
CV $(\%)$ & 7,23 & 2,48 & 4,63 & 9,21 & 78,88 \\
\hline
\end{tabular}

NS - Não significativo $(\mathrm{P}>0,05)$

Fonte: Elaboração dos autores.

Os resultados observados na Tabela 3 mostram que a adição on top de diferentes níveis do complexo enzimático, fornecidos na dieta de galinhas poedeiras não proporcionaram alterações nas porcentagens de gema, albúmen e casca, mostrando que o fornecimento deste complexo, não influenciou no aproveitamento ou transferência de nutrientes que pudesse alterar a porcentagem de cada constituinte dos ovos.

Tabela 3. Resultados das porcentagens de gema, albúmen e casca dos ovos provenientes de galinhas poedeiras comerciais alimentadas com diferentes níveis de complexo enzimático.

\begin{tabular}{cccc}
\hline Níveis do complexo & & Porcentagem & \\
\cline { 2 - 4 } enzimático & Gema & Albúmen & Casca \\
\hline Controle & 27,73 & 63,03 & 9,24 \\
$50 \mathrm{ppm}$ & 27,73 & 63,09 & 9,19 \\
$100 \mathrm{ppm}$ & 27,26 & 63,58 & 9,16 \\
$150 \mathrm{ppm}$ & 27,38 & 63,58 & 9,04 \\
$200 \mathrm{ppm}$ & 27,50 & 63,22 & 9,27 \\
\hline Efeito & $\mathrm{NS}$ & $\mathrm{NS}$ & $\mathrm{NS}$ \\
CV $(\%)$ & 2,89 & 1,40 & 3,21 \\
\hline
\end{tabular}

NS - não significativo pelo teste Tukey $(\mathrm{P}>0,05)$.

Fonte: Elaboração dos autores.

Quanto às características de qualidade dos ovos (Tabela 4) observa-se que a adição on top de diferentes níveis do complexo enzimático não proporcionou alterações nas características externas e internas dos ovos, como é mostrado pela espessura de casca, cinza da casca, gravidade específica e unidade Haugh. Isto mostra que a quantidade de nutrientes fornecida pela dieta controle atendeu as 
necessidades de produção e de qualidade dos ovos. Resultado semelhante foi observado por Araújo et al. (2008) que ao adicionar complexo enzimático constituído pelas enzimas alfa-galactosidase, galactomananase, xilanase e beta-glucanase na dieta de galinhas poedeiras não observaram efeito $(\mathrm{P}>0,05)$ sobre o peso final das aves, o consumo de ração, a produção de ovos, a massa de ovos, a conversão por massa e por dúzia de ovos e a gravidade específica.

Tabela 4. Resultados de espessura de casca, gravidade específica, unidade Haugh e porcentagem de cinza das cascas dos ovos provenientes de galinhas poedeiras comerciais alimentadas com diferentes níveis de complexo enzimático.

\begin{tabular}{ccccc}
\hline $\begin{array}{c}\text { Níveis de complexo } \\
\text { enzimático }\end{array}$ & $\begin{array}{c}\text { Espessura casca } \\
(\mathrm{mm})\end{array}$ & $\begin{array}{c}\text { Gravidade } \\
\text { específica }\end{array}$ & Unidade Haugh & $\begin{array}{c}\text { Cinzas das cascas } \\
(\%)\end{array}$ \\
\hline Controle & 0,38 & 1,085 & 73,60 & 92,97 \\
$50 \mathrm{ppm}$ & 0,38 & 1,081 & 72,30 & 92,79 \\
$100 \mathrm{ppm}$ & 0,37 & 1,083 & 70,90 & 91,63 \\
$150 \mathrm{ppm}$ & 0,37 & 1,083 & 71,60 & 91,25 \\
$200 \mathrm{ppm}$ & 0,38 & 1,084 & 72,70 & 92,11 \\
\hline Efeito & $\mathrm{NS}$ & $\mathrm{NS}$ & $\mathrm{NS}$ & $\mathrm{NS}$ \\
$\mathrm{CV}(\%)$ & 3,32 & 0,45 & 5,06 & 2,12 \\
\hline
\end{tabular}

NS - não significativo pelo teste Tukey $(\mathrm{P}>0,05)$.

Fonte: Elaboração dos autores.

Enquanto que Dipeolu et al. (2005) ao adicionar antibióticos + enzimas ( $\alpha$-amilase, xilanase, protease e pectinase) na alimentação de galinhas poedeiras, observaram uma melhor unidade Haugh em relação aos ovos provenientes de aves do tratamento controle, sendo que os demais parâmetros de qualidade interna e externa dos ovos não foram influenciados.

Quanto aos resultados do conteúdo da digesta e das fezes (Tabela 5) observa-se que a adição de diferentes níveis de inclusão do complexo enzimático na ração de poedeiras comerciais proporcionou um aumento linear $(\mathrm{P}<0,01 ; \mathrm{Y}=0,6311111+0,108889$ $\mathrm{X})$ no $\mathrm{pH}$ do conteúdo do intestino delgado das aves. Apesar do aumento do $\mathrm{pH}$ do intestino delgado, este não prejudicou o desempenho das aves, visto que é sabido que $\mathrm{pH}$ mais baixo melhora a absorção de minerais e inibem o desenvolvimento de microrganismos indesejáveis. Isto não foi observado pelos resultados da porcentagem de ovos trincados, espessura da casca, matéria mineral na casca e fezes e microbiologia da digesta do intestino delgado.

Foi observado também que a utilização de níveis crescentes do complexo enzimático também proporcionou uma redução $(\mathrm{P}<0,05 ; \mathrm{Y}$ $=0,2483867-0,38124444 \mathrm{X})$ na viscosidade do conteúdo do intestino delgado. Segundo Yin et al. (2000) a adição de enzimas é capaz de reduzir algumas propriedades anti-nutricionais presentes nos alimentos, como os PNAs, que possuem a capacidade de aumentar a viscosidade da digesta, por apresentar alta capacidade de se ligar à água, formando um gel viscoso, dificultando assim a ação das enzimas e a absorção dos nutrientes já digeridos. Pelos resultados obtidos, mostra-se que apesar da enzima melhorar as condições da digesta quanto à viscosidade, isto não se mostrou em termos de desempenho e qualidade dos ovos. 
Tabela 5. Resultados do $\mathrm{pH}$ e viscosidade do conteúdo do intestino delgado e, matéria seca e matéria mineral das fezes de poedeiras alimentadas com diferentes níveis complexo enzimático.

\begin{tabular}{ccccc}
\hline $\begin{array}{c}\text { Níveis complexo } \\
\text { enzimático }\end{array}$ & pH digesta & $\begin{array}{c}\text { Viscosidade da } \\
\text { digesta }(\mathrm{cP})^{1}\end{array}$ & $\begin{array}{c}\text { Matéria seca fezes } \\
(\%)\end{array}$ & $\begin{array}{c}\text { Matéria mineral } \\
\text { fezes }(\%)\end{array}$ \\
\hline Controle & 6,30 & 2,50 & 23,64 & 35,94 \\
$50 \mathrm{ppm}$ & 6,36 & 2,38 & 22,62 & 35,11 \\
$100 \mathrm{ppm}$ & 6,46 & 2,00 & 23,16 & 36,84 \\
$150 \mathrm{ppm}$ & 6,48 & 1,79 & 23,20 & 35,37 \\
$200 \mathrm{ppm}$ & 6,51 & 1,85 & 21,94 & 34,33 \\
\hline Efeito & Linear $^{2}$ & Linear $^{3}$ & $\mathrm{NS}$ & $\mathrm{NS}$ \\
$\mathrm{CV}(\%)$ & 2,63 & 32,16 & 7,57 & 5,95 \\
\hline
\end{tabular}

${ }^{1} \mathrm{cP}=$ centipoise

${ }^{2}$ Significativo pelo teste de Tukey $(\mathrm{P}<0,01)$ - Equação $\mathrm{pH}=0,6311111+0,1088889 \mathrm{X}$

${ }^{3}$ Significativo pelo teste de Tukey $(\mathrm{P}<0,05)$ - Equação viscosidade $=0,2483867-3812444 \mathrm{X}$.

Fonte: Elaboração dos autores.

Quanto à matéria seca das fezes não foi observada diferença entre os diferentes níveis de inclusão do complexo enzimático. Apesar da menor viscosidade da digesta, esta não proporcionou alterações na matéria seca das fezes. Resultados semelhantes foram encontrados por Murakami et al. (2007) ao trabalharem com poedeiras comerciais jovens com adição de diferentes níveis de inclusão do complexo enzimático. A matéria mineral das fezes também não foi influenciada pela ação das enzimas, mostrando que apesar do complexo enzimático proporcionar um maior $(\mathrm{P}<0,05) \mathrm{pH}$ da digesta, esta não proporcionou uma pior absorção dos minerais, a ponto de promover diferenças significativas no conteúdo destes nas fezes. Outro fator que poderia ter influenciado a matéria mineral é a utilização da fitase, que pode hidrolisar os quelatos no trato gastrointestinal, disponibilizando fósforo inorgânico (GREINER; CARLSSON; ALMINGER, 2000), cálcio, magnésio, zinco e ferro.

$\mathrm{Na}$ análise da microbiologia do intestino delgado, pode-se observar que não houve efeito $(\mathrm{P}>0,05)$ da adição do complexo enzimático na dieta de galinhas poedeiras quanto a quantidade de Lactobacillus e coliformes totais e fecais, sendo que a salmonela foi ausente em todos os testes (Tabela 6). Apesar de apresentar um $\mathrm{pH}$ menos ácido, os tratamentos com o fornecimento do complexo enzimático não proporcionou diferenças na quantidade de Lactobacillus. Isto mostra que as alterações provocadas pela adição do complexo enzimático no $\mathrm{pH}$ e viscosidade foram pequenas, que não chegaram a influenciar na qualidade das fezes e na microbiologia intestinal. 
Tabela 6. Resultados da microbiologia (expresso $\log _{10}$ ) do intestino delgado de poedeiras alimentadas com diferentes níveis de complexo enzimático.

\begin{tabular}{ccccc}
\hline Níveis complexo & $\begin{array}{c}\text { Lactobacillus spp } \\
\text { enzimático }\end{array}$ & Salmonella spp & \multicolumn{2}{c}{ Coliformes (NMP/g) } \\
\cline { 4 - 5 } Controle & 6,65 & Ausente & 1,39 & Fecais \\
$50 \mathrm{ppm}$ & 7,12 & Ausente & 2,24 & 2,00 \\
$100 \mathrm{ppm}$ & 7,22 & Ausente & 2,60 & 1,98 \\
$150 \mathrm{ppm}$ & 7,09 & Ausente & 2,13 & 2,27 \\
$200 \mathrm{ppm}$ & 7,05 & Ausente & 2,05 & 1,67 \\
\hline Efeito & $\mathrm{NS}$ & --- & $\mathrm{NS}$ & $\mathrm{NS}$ \\
CV $(\%)$ & 7,55 & --- & 40,64 & 41,32 \\
\hline
\end{tabular}

NS - não significativo pelo teste Tukey $(\mathrm{P}>0,05)$.

Fonte: Elaboração dos autores.

\section{Conclusões}

Os resultados do presente trabalho permitem concluir que a adição on top do complexo enzimático nas rações à base de milho e farelo de soja em galinhas de postura velhas não proporcionou melhorias no desempenho, qualidade dos ovos, fezes e na microbiologia intestinal das aves.

\section{Referências}

ALMIRALL, M.; FRANCESCH, M.; PEREZVENDRELL, A. M.; BRUFAU, J.; ESTEVE-GARCIA, E. The difference in intestinal viscosity produced by barley and B-glucanase alter digesta enzyme activities and ileal nutrient digestibilities more in broilers chicks than in cocks. Journal of Nutrition, Bethesda, v. 125, n. 4, p. 947-955, 1995.

ASSOCIATION OF OFFICIAL ANALYTICAL CHEMISTS - AOAC. Official methods of analysis. 15. ed. Washington: AOAC, 1990.

ARAÚJO, D. M.; SILVA, H. V.; MIRANDA, E. C.; ARAÚJO, J. A.; COSTA, F. G. P.; TEIXEIRA, E. N. M. Farelo de trigo e complexo enzimático na alimentação de poedeiras semipesadas na fase de produção. Revista Brasileira de Zootecnia, Viçosa, v. 37, n. 5, p. 843-848, 2008.

BEDFORD, M. R. Exogenous enzymes in monogastric nutrition - their current value and future benefits. Animal Feed Science and Technology, Amsterdam, v. 86, n. 1, p. 1-13, 2000.

COSTA, F. G. P.; CLEMENTINO, R. H.; JÁCOME, I. M. T. D.; NASCIMENTO, G. A. J.; PEREIRA, W. E.
Utilização de um complexo multienzimático em dietas de frangos de corte. Ciência Animal Brasileira, Goiânia, v. 5, n. 2, p. 63-67, 2004.

DIPEOLU, M. A.; ERUVBETINE, D.; OGUNTONA, E. B.; BANKOLE, O. O.; SOWUNMI, K. S. Comparison of effects of antibiotics and enzyme inclusion in diets of laying birds. Archivos de Zootecnia, Córdoba, v. 54, n. 205, p. 3-11, 2005.

FREITAS, E.; FUENTES, M. D. F. F.; ESPÍNDOLA, G. B. Efeito da suplementação enzimático em rações a base de milho/farelo de soja sobre o desempenho de poedeiras comerciais. Revista Brasileira de Zootecnia, Viçosa, v. 29, n. 4, p. 1103-1109, 2000.

GREINER, R.; CARLSSON, N. G.; ALMINGER, M. L. Stereospecificity of myo-inositol hexakisphosphate dephosphorylation by a phytate-degrading enzyme of Escherichia coli. Journal of Biotechnology, Bielefeld, v. 84, n. 1, p. 53-62, 2000.

MURAKAMI, A. E.; FERNANDES, J. I. M.; SAKAMOTO, M. I.; SOUZA, L. M. G.; FURLAN, A. C. Efeito da suplementação enzimática no desempenho e qualidade de ovos de poedeiras comerciais. Acta Scientiarum Animal Science, Maringá, v. 29, n. 2, p. 165 172, 2007.

ROSTAGNO, H. S.; ALBINO, L. F. T.; DONZELE, J. L.; GOMES, P. C.; OLIVEIRA, R. F.; LOPES, D. C.; FERREIRA, A. S.; BARRETO, L. S. T. Tabelas Brasileiras para aves e suínos. Composição de alimentos e exigências nutricionais. 2. ed. Viçosa: Universidade Federal Viçosa, 2005. 186 p.

SIQUEIRA R. S. Manual de microbiologia de alimentos. Brasília: EMBRAPA/SPI: Rio de Janeiro; EMBRAPA/ CTAA, 1995. 159 p. 
SOUZA, P. A.; SOUZA, H. B. A.; BROGNONI, E.; ROCHA, O. E. Influência da idade da ave sobre a qualidade do ovo. Científica, São Paulo, v. 22, n. 2, p. 217-226, 1994.

UNIVERSIDADE FEDERAL DE VIÇOSA - UFV. Sistema de análises estatísticas e genéticas - SAEG. Versão 8.0. Viçosa, MG, 2000, 142 p.
YIN, Y. L.; McEVOY, J. D. G.; SCHULZE, H.; HENNIG, U.; SOUFFRANT, W. B.; McCRACKEN, K. J. Apparent digetibility (ileal and overall) of nutrients and endogenous nitrogen losses in growing pigs fed wheat (var. Soissons) or its by-products without or with xylanase supplementation. Livestock Production Science, Amsterdam, v. 62, v. 2, p. 119-132, 2000. 